\title{
Salmonella: A Common Contaminant of Chicken Shawarma in RasBeirut Restaurants
}

\author{
Hanin Banna ${ }^{1}$ and Tarek Nawas ${ }^{1} *$ \\ 1: Natural Sciences Department, Lebanese American University, Beirut - Lebanon
}

\begin{abstract}
Samples of the popular chicken shawarma sandwiches from ten reputed restaurants in the Hamra region of Ras Beirut, were tested for contamination with Salmonella. The sandwiches tested were those regularly offered to customers, but were of two categories, with and without a garlic spread that is usually added to this type of Sandwiches. Salmonellawas isolated from sandwiches taken from 3 different restaurants (30\%). Two of the three were isolated from part not containing garlic while the third was isolated from a sample that contained the garlic spread. The isolation of Aeromonashydrophila and Escherichia coli, two other major causes of gastroenteritis in man, from sandwiches from two other restaurants, is a clear indication that this type of sandwich tends to be easily contaminated due to many reasons discussed in this study. It is recommended that strict measures be taken by the health care authorities to ensure the safety of the numerous consumers of this commonly favored type of food.
\end{abstract}

Keywords: Chicken shawarma sandwiches, Cross-Contamination,Food poisoning, Food safety, Salmonella.

\section{Introduction}

Food contamination occurs during production, processing, or inappropriate handling of food even at home.Ingestion of food contaminatedwith certain bacteria, viruses, parasites or any of their toxins will lead to food poisoning (1). Symptoms of food poisoning such as vomiting, nausea, cramps, diarrhea with or without blood, abdominal pain, or fever might appear after hours or even few days after consuming contaminated food. They are often mild and a person can recover alone at home but some people need to refer to the hospital. Risks of getting an infection are higher in infants or children since they don't have a well-developed immune system, and in old people as the response of their immune system becomes weaker $(2,3,4)$.

Food poisoning is mainly caused by the contamination of specific types of food by certain microbes. For instance, Campylobacter spp. can be present in meat and poultry,Clostridium botulinum may be present in improperly canned food and smoked or salted fish andShigella can be found in rawmeat, contaminated water and in seafood. However, more commonlyis the presence of Salmonellaspp. in raw or contaminated meat, poultry, milk, or egg yolk and in insufficiently cooked food $(4,5)$.

Salmonella species are Gram-negative, flagellated facultative anaerobic bacilli. There are about 2579 known serotypes that current classification considers as separate species $(6,7,8)$. More than half of the Salmonella thatcommonly contaminate food and lead to food poisoning are members of the Salmonella enterica subspecies enterica serotypes (9).Pathogenic salmonellae ingested in food survive passage through the gastric acid barrier and invade the mucosa of the small and large intestine and may produce toxins. Invasion of epithelial cells stimulates the release of pro-inflammatory cytokines which induce an inflammatory reaction (10). The acute inflammatory response causes diarrhea and may lead to ulceration and destruction of the mucosa. The bacteria can disseminate from the intestines to cause systemic disease. Signs and symptoms of salmonella infection generally last four to seven days, although it may take several months for the bowels to return to normal (10).

Salmonella Enteritidis (Salmonella entericasubspecies enterica, serotypeEnteritidis) is the most common serotype of Salmonella contaminating food. The increased prevalence in poultry products made Salmonella Enteritidis a food-safety issue as of the 1970s.Salmonella Typhimuriumis the second most common serotype associated with food borne illness and the third most frequently identified with chicken. Salmonella Newport is the third most common Salmonella serotype associated with contaminated turkey,while. Salmonella Javiana is considered to be the fourth most common serotype associated with food borne illness. A report on Salmonella serotypes from the Food Safety and Inspection Service (FSIS), the food safety arm of the U.S. Department of Agriculture, indicated that this strain is not often associated with products regulated by the agency (11), but is associated with exposure to amphibians and also linked to contaminated mozzarella cheese, watermelon, bass, poultry, lettuce and tomatoes. Finally, Salmonella Heidelberg is the fifth most common Salmonella serotype associated with food borne illness and the second most frequently associated with human health issues and poultry, according to a recent report from the FSIS. Salmonella Heidelberg has caused recent poultry recalls and food borne illness outbreaks $(11,12)$. 
Salmonella food poisoning ranks amongst the first causes of foodborne illnesses in Lebanon. Food poisoning outbreaks are often reported from all parts of the country. Outbreaks have been officially reported to occur in the governorates of Beirut, the south, Mount Lebanon and Bekaa (13). Lebanese statistics show that SalmonellaEnteritidis ranked as the most prevalent serotype of Salmonella from clinical isolates followed by Salmonella Typhimurium in the years 2011 and 2012 (13).

The purpose of this study was to check for the presence of Salmonella spp. in a popular type of fast food: Chicken shawarma in the RasBeirut area, a very busy area of the Lebanese capital Beirut. The study was initiated after noting that the process of preparing the poultry meat and the sandwiches did not involve proper cooking and was not fully abiding to standard methods of hygiene.

\subsection{Sources of specimens:}

\section{Materials And Methods}

The chicken shawarma sandwiches used in the study were purchased from ten of the most reputed restaurants in the Hamra region of the Ras Beirut area during the months of February and March, 2016. The purchase was made by university students who asked that after the regular sandwich be prepared, it would becut in half with only one half to include the garlic spread, usually added to these sandwiches. The sandwiches were then immediately carried to the microbiology laboratory where they were processed within 10 to 15 minutes after purchase.

\subsection{Processing of specimens:}

The method recommended by the WHO for processing of food for isolation ofSalmonella was used (14) with modifications as to the media used to increase the chances of isolation of small numbers of the organism. Each of the two parts of the ten sandwiches (with and without the garlic spread) was processed as a separate specimen and all specimens were processed in the same way. The content of each sandwichwas completely emptied into a stomacher bag, mixed with $10 \mathrm{ml}$. of saline $(0.85 \% \mathrm{NaCl})$ and put in the stomacher for homogenization. Theextracts were thenimmediately cultured. Asterile swab was used to inoculate the MacConkey agar (MA- a semi-selective and differential medium)and Salmonella -Shigella agar (SSA- a selective and enrichment medium) plates. Moreover, $1 \mathrm{ml}$ of the extract was used to inoculate a $10 \mathrm{ml}$ selenite broth tube (a Salmonella enrichment broth). The plates and tubes were then incubated for $18-24 \mathrm{hrs}$ at $36.0^{\circ} \mathrm{C} \pm$ $1{ }^{\circ} \mathrm{C}$. After incubation, the plates were checked for the growth of suspected Salmonella colonies and aloop full from the relevant selenite broth tube was used to inoculate new MA and SSA plates which werealso incubated for $18-24 \mathrm{hrs}$ at $36.0^{\circ} \mathrm{C} \pm 1^{\circ} \mathrm{C}$.

All suspected colonies (colorless colonies from MA or colorless colonies with black centers from SSA) from all plates of the same specimen, were isolated on Trypticase soy agar (TSA) plates and incubated at $36.0^{\circ} \mathrm{C}$ $\pm 1^{\circ} \mathrm{C}$ for $18-24 \mathrm{hrs}$. Theisolated organisms were then identified using regular biochemical tests as recommended (15), and their definitive identity confirmed by using API20E strips (BioMérieux- France).

\section{Results}

After carrying out the preceding experiment, three out of the ten samples $(30.0 \%)$ showed confirmed growth ofSalmonella colonies. The isolates were from three different restaurants. Two of the Salmonella isolates were from the sandwich section that did not contain garlic while the other half that did contain the garlic did not grow the organisms even after enrichment (in the selenite enrichment broth). The third positive isolate, however, was grown from the part of the sandwich that contained the garlic spread and after enrichment, while it was not grown from the other section of the sandwich that did not contain the garlic spread. Moreover, and although this study aimed at only detecting the presence of Salmonella spp. In the tested samples, it was also observed that from one restaurant both sections of the sandwich (with and without garlic) heavily grew the organism Aeromonashydrophila. A sandwich from a fifth restaurant grew Escherichia colifrom the part of the sandwich that did not contain the garlic spread.

\section{Discussion}

Salmonella, Clostridium perfringens and Campylobacterinfections are among the most important food safety hazards $(2,16)$. These bacteria account for more than 90 percent of all reported cases of bacteria-related food poisonings worldwide. Reported cases of Salmonella and Campylobacter infections are believed to represent only a fraction of the true number of cases (17).

Although many types of contaminated foods can be the cause of Salmonella gastroenteritis, yet poultry and their products are an important vehicle for human Salmonella infections in the United States, as reported by the Department of health and human services (18), and worldwide (17, 19). The contamination of chicken with Salmonella may occur at any stage of the standard poultry slaughter stages, but was found to be highest during the defeathering stage (20). 
A favorite type of fast food for the Lebanese is shawarma sandwiches. Shawarma can be originally traced back to Turkey, where it was called "çevirme", which means "turning", but the dish itself is usually called döner kebab, meaning "turning kebab". It has become more popular among consumers of fast foods in the Middle East, Europe, Canada, and other countries (21). Chicken shawarma is basically a wrap of shredded marinated chicken, prepared by alternately stacking strips of pieces chicken on a rotating vertical skewer rod. The strips are roasted from the outside, while most of the inside remains rare. Shavings are cut off the block for serving, and the remaining block of chicken is kept heated on the rotating skewer rod. Chicken shawarma sandwiches contain sliced chicken seasoned with peppers and with a special garlic spread (prepared with local mayonnaise and other ingredients that may differ from one restaurant to another) and served in a pita bread wrap. Shawarma sandwiches are similar to donairs, and such types of foods are subjected to contamination with pathogens during preparation, processing, and serving (22). These foods are manipulated extensively during processing and therefore have a potential for high bacterial contamination levels on the surface of the meat, as well as the inside. As a result, there is an increased risk of pathogens surviving and transferring not only by cross-contamination, but also by undercooking as observed in this kind of fast-food industry (23)

The results of this study indicated that 3 sandwiches obtained from 3 different restaurants (30\%) in the area tested were contaminated with Salmonellaspp.. Two positive samples were from the part of the sandwich that did not contain the garlic spread while one positive sample was obtained from the part that contained the garlic spread. Garlic is widely known for its antibacterial properties with a notable effect on Salmonella spp. (24). Accordingly, it is presumed that an ordinary shawarma chicken sandwich, even if slightly contaminated, should be safe to consume as the garlic will reduce any bacterial count to a dose that is harmless. The garlic spread, however, is not prepared in the same way in all restaurants and the amount of garlic included may differ in different preparations. The presence of mayonnaise as a major component of the spread may affect the outcome. If mayonnaise composed the bigger part of the spread then it might have served as a rich culture medium that allowed the Salmonella spp. present to increase in number to a count that wasclinically significant. This explains the positive result obtained from a garlic spread containing part of the sandwich from one of the restaurants included in the study. The prepared batch of this mayonnaise rich spread may have been contaminated by the workers and served as a source of cross contamination whenever that spread was used.

The presence of one sample contaminated with E.coliand another with Aeromonashydrophilafrom two additional restaurants (although not particularly looked for, but showed prevalent growth), was another indication of bacterial contamination of the chicken shawarma and shed light on the poor hygiene of the workers responsible for processing and preparingthe sandwiches.

A study conducted in North Jordan in 2014, to isolate and identify bacterial pathogens from shawarma sandwiches (meat and chicken) sold to the public, also revealed that $26.3 \%$ of Shawarma sandwiches were also contaminated with Salmonella (23). The prevalence of Salmonella in chicken in the present study was much higher than the findings reported from Morocco $(25,26)$.

The health hazard from Salmonella must not be underestimated. The fact that Salmonella was detected in samples from supermarkets, where chicken are displayed under refrigeration, shows that the spread of infection was not only confined to seemingly unhygienic environments (27), but also that the animal itself mayhave been initially contaminated (18).Moreover, it was suggested that to prevent contamination by Salmonella control measures must be taken at all stages of the food chain, from agricultural production, to processing, manufacturing and preparation of foods in both commercial establishments and at home (29).

\section{Conclusion}

This study confirms that chicken shawarma sandwiches may serve as a source of foodborne pathogens and accordingly a potential public health hazard. Corrective action needs to be employed to minimize the risk of consuming this type of fast food, knowing that even small doses of the organism may lead to food poisoning (30). Such action must aim at minimizing the bacterial contamination during the production of the shawarma chicken (cleaning, cutting, seasoning and stacking), its cooking and serving. Regular surveillance by the public health regulatory bodies will ensure compliance with WHO and ISO standards for food safety. More attention should be given to the cleanliness of utensils used in preparing the sandwiches (rod, knives, etc.) in addition to the personal hygiene of the workers preparing and stuffing the sandwiches. Awareness to minor issues (like making sure that the garlic spread contained the right amount of garlic as compared to the mayonnaise added), may also serve to reduce the contamination in these sandwiches. Availability of epidemiologic data, by similar studies about the prevalent pathogens and their transmission in food, will provide solid basic information about the potential dangers of not implementing standard procedures and will serve as a basis for adopting new regulations that will ensure the safety of the consumer. 


\section{References}

[1]. M Addis and D Sisay, A review on major food borne bacterial illnesses,J Trop Dis 3 (4), 2015 , 176. doi:10.4176/2329891X.1000176.

[2]. Centers for Disease Control and Prevention, What is Salmonellosis, Atlanta, Georgia, U.S. Department of Health and Human Services, CDC, 2015. Available at: https://www.cdc.gov/salmonella/general/index.html

[3]. World Health Organization - FAO, Laboratory Protocol, In: Isolation of Salmonella spp. from food and animal faeces. 5th Ed. June 2010. Pages 4-8, 9-13, Available at: http://www.antimicrobialresistance.dk/data/images/protocols/isolation_of_salm_220610.pdf

[4]. CM Logue and CW Nde, Salmonella contamination of turkey from processing to final product - A process to product perspective, Foodborne Pathogens and Disease, 4(4), 2007 491-504

[5]. CO Gill and M Badoni, Recovery of bacteria from poultry carcasses by rinsing, swabbing or excision of skin, Food Microbiol. 22, 2005, 101-107

[6]. AAndino and I Hanning,Salmonella enterica: Survival, colonization, and virulence differences among serovars, Scientific World Journal, 2015,(Article ID 520179). Available at: http://dx.doi.org/10.1155/2015/520179.

[7]. MJ Blaser and LS Newman,A Review of Human Salmonellosis: I. Infective Dose. Clin. Inf. Dis. 4(6), 1982, $1096-1106$.

[8]. SM Pires, L de Kneg and T Hald, Estimation of the relative contribution of different food and animal sources to human Salmonella infections in the European Union. 2011. Available from: http://www.efsa.europa.eu/en/supporting/doc/184e.pdf.

[9]. Food Safety and Inspection Service - FSIS, A comparison of Salmonella serotype incidence in FSIS-regulated products and salmonellosis cases, 2010. Available at: http://www.fsis.usda.gov/wps/wcm/connect/746242e6-e309-4f7c-88e374f28721f392/Serotype_Incidence_and_Salmonellosis.pdf?MOD=AJPERES

[10]. ST Cowan, ST, and KJ Steel, Identification of medical bacteria. University Press, Cambridge, MA. 1965.

[11]. B Oumokhtar, Bacteriological quality of commercial meat, meat offal, carcasses and oysters in Rabat, doctoral diss.,ChouaibDoukkali University, Faculty of Sciences, El Jadida, Morocco, 2000.

[12]. PA Grimont and FX Weill, Antigenic Formulae of the Salmonella Serovars, WHO Collaborating Centre for Reference and Research on Salmonella, Institut Pasteur, Paris, France, 2007.

[13]. B Malorny, E Hauser and R Dieckmann, New approaches in subspecies-level Salmonella classification, S. Porwollik, (Ed), Salmonella From Genome to Function,., pp. 1-23, Academic Press, Norfolk, UK, 2011.

[14]. CN Okafo, VJ Umoh, and M Galadima, Occurrence of pathogens on vegetables harvested from soils irrigated with contaminated streams. Sci Total Environ 311, 2010, 49-56

[15]. R Feldberg, S Chang, A Kotik, M Nadler and Z Neuwirth, In vitro mechanism of inhibition of bacterial cell growth by allicin, Antimic. Agents Chemother. 32, 1988, 1763-1768. DOI: 10.1128/aac.32.12.1763.

[16]. BA Sackey, P Mensah, E Collison and ES Dawson, Campylobacter, Salmonella, Shigellaand Escherichia coli in live and dressed poultry from metropolitan Accra. Int. J. Food Microbiol. 71, 2001, 2128.

[17]. B Coburn, GA Grassl and BB Finlay, Salmonella, the host and disease: a brief review. Immunol. Cell Biol. 85, 2007 112-118. DOI: 10.1038/sj.icb.7100007

[18]. Mayo Clinic Staff, Food Poisoning, Mayo Clinic (07), 2014. Available at: http://www.mayoclinic.org/diseasesconditions/foodpoisoning/basics/definitions/con-20031705.

[19]. N Cohen, H Ennaji, B Bouchrif, M Hassar, and H Karib, Comparative study of microbiological quality of raw poultry meat at various seasons and for different slaughtering processes in Casablanca (Morocco). J. Appl. Poult. Res. 16 (4), $2007,502-508$. doi:10.3382/japr.2006-00061

[20]. Centers for Disease Control and Prevention,Foodborne illness from Salmonella and Campylobacter associated with poultry, Atlanta, Georgia, U.S. Department of Health and Human Services, CDC, $2011 . \quad$ Available at: http://www.fsis.usda.gov/PDF/Salmonella_Campylobacter_011811.pdf.

[21]. SK Eng, PPusparajah, NS AbdMutalib, HL Ser, KG Chan and LH Lee,Salmonella: A review on pathogenesis, epidemiology and antibiotic resistance,Frontiers in Life Science. 8 (3) 2015, 284-293. DOI:10.1080/21553769.2015.1051243

[22]. Mayo Clinic Staff, Salmonella Infection. Mayo Clinic (04), 2014. Available at: http://www.mayoclinic.org/diseasesconditions/salmonella/basics/definition/con-20029017.

[23]. L Nimri, F Abu Al Dahab and R Batchoun, Foodborne bacterial pathogens recovered from contaminated shawarma meat in northern Jordan, J Infect Dev Ctries. 8(11), 2014, 1407-1414. DOI:10.3855/jidc.4368

[24]. Pulse Net Lebanon. Annual Report, PulseNet International (foodborne diseases tracking network), 2011- 2012. Available at: http://www.pulsenetinternational.org/assets/Uploads/PulseNetLebanon20112012-rev-Final-Feb-3-2014.pdf

[25]. Centers for Disease Control and Prevention, Foodborne Diseases Active Surveillance Network (FoodNet): FoodNet Surveillance Report for 2012 (Final Report), Atlanta, Georgia: U.S. Department of Health and Human Services, CDC, 2014. Available at: http://www.cdc.gov/foodnet/PDFs/2012_annual_report_508c.pdf

[26]. Food and Agriculture Organization (FAO) and World Health Organization (WHO), Microbiological Risk Assessment Series: Salmonella and Campylobacter in chicken meat. Meeting Report, $2009 . \quad$ Available at: http://apps.who.int/iris/bitstream/10665/44211/1/9789241547901_eng.pdf?ua=1

[27]. Food and Agriculture Organization (FAO), Poultry Development Review: Poultry and poultry products: Risks for human health by M Ventura da Silva, FAO Document Repository, 2013. Available at: http://www.fao.org/docrep/019/i3531e/i3531e.pdf

[28]. S Robinson S, TheBig Five: Most Common Salmonella Strains in Foodborne Illness Outbreaks. Food Safety News (8), 2013. Available at: http://www.foodsafetynews.com/2013/08/the-five-most-common-salmonella-strains/\#.Vi5Arfk733U

[29]. World Health Organization MEDIA Centre, Fact sheet $\mathrm{N}^{\circ} 139$ : Salmonella (non-typhoidal), 2013 Available at: http://www.who.int/mediacentre/factsheets/fs139/en/

[30]. Food Protection Services, BC Center for Disease Control, Guideline for the Safe Preparation and Serving of Donairs, Shawarmas and Similar Products, Vancouver: BC Center for Disease Control, $2012 . \quad$ Available: http://www.bccdc.ca/NR/rdonlyres/7AE4EAEA-9A72-437C- 8134- 0B8E7EDFA2A3/0/Guidelines_Donairs_Final_June2012.pdf. Accessed September 25, 2013 